\title{
A Highly Reliable, Modular, Redundant and Self-Monitoring PSU Architecture
}

\section{Bertalan Beszédes, Károly Széll, György Györök}

\author{
Alba Regia Technical Faculty, Óbuda University \\ Budai út 45, H-8000 Székesfehérvár, Hungary \\ \{beszedes.bertalan; szell.karoly; gyorok.gyorgy\}@amk.uni-obuda.hu
}

\begin{abstract}
The production of highly reliable, electronic devices is a source for significant environmental emissions and energy consumption. A modern, cost-effective and modular design can enhance product maintainability and lifetime. Many end-users would certainly be willing to devote more resources (money) for a device they use, if, in return, they could extend the life of the device. This paper introduces the architecture for a high-reliability, modular, end-user-configurable, redundant power supply, based on these principles.
\end{abstract}

Keywords: redundant; robust; self-monitoring; embedded system; modular PSU; high reliable

\section{Introduction}

Despite the arrival of many renewable energy sources, the vast majority of the world's energy supply is still provided by fossil fuels, the extraction and use involves the release of large amounts of greenhouse gases into the atmosphere. Therefore, improving energy efficiency is currently also the most effective means of trying to fight climate change. While the world's energy efficiency is improving [1], so is the amount of wasted energy, decreasing. As a result of the growth of Earth's population and global economy, humanity's total energy consumption (global primary energy demand) continues to rise. And because of the predominance of fossil fuels, polluting energy sources in the global energy mix, it is also leading to an increase in greenhouse gas emissions, which have recently grown at the fastest pace since 2013 .

Technological advances have made it possible to increase energy efficiency, which significantly reduces emissions while increasing energy use. Energy efficiency could be improved at a much higher rate, with technologies that are already available, but rarely used [2] [3]. 
According to the International Energy Agency (IEA), the potential is enormous, and by taking advantage of it alone, we could stop the rise of greenhouse gas emissions after 2020. However, according to the latest surveys, the world is moving further and further away from this goal [4] [5].

According to the International Energy Agency's Efficient World Strategy (EWS), at least a 3\% improvement would be needed, each year, to meet global climate and sustainability goals. The 3\% has only been realized once, in 2015 and the pace has slowed gradually, thereafter.

By using cost-effective technologies [6], the pace of energy efficiency improvement can be increased to a much higher level. Design principles like modular device design, maintainability and traceability can serve this goal. Digitalization and remote supervision systems are closely linked to these features [7].

The continuous development of end-user technological capabilities also supports the need for modular, easy-to-maintain designs [8]. There is a niche market for manufacturers to ensure user-friendliness and repair-ability of civil and industrial devices - in exchange for some extra cost. The authors hope that the modular design and the installation and repair manuals of the devices will come back into vogue.

In terms of robustness of such systems successful results have been achieved in the field of fault diagnosis and fault tolerant techniques [9] - [11]. Basically, we can define the following categories for fault diagnosis methods:

- Model-based [12]-[14]

The outputs of the system-model and the outputs of the real system is compared

- $\quad$ Signal-based [15]-[18]

A diagnostic decision is made based on the measured signal

- Knowledge-based [19]-[21]

A large volume of historic data is needed

- Hybrid and active [22]-[24]

Combination of the previous methods based on their advantages

The basic fault types are as follows [25] [26]:

- Actuator fault

- Sensor fault

- Plant fault

In the literature, several practical solutions can be found [27] [28]. 


\section{Architecture}

\subsection{Power Supply Unit}

\subsubsection{Modular Power Supply Unit}

Figure 1 shows a block diagram of a battery-powered modular power supply (PSU) controlled by a microcontroller (MCU). The external source of energy can be the electricity grid or renewable energy source. The battery charger is responsible for properly charging and discharging the energy storage unit. The function of a DC/DC converter is to ensure the voltage level of the battery or external power source to meet customer needs.

In case of $\mathrm{AC}$ external power source or a load that requires $\mathrm{AC}$ power supply, the proper battery charger and $\mathrm{AC} / \mathrm{DC}, \mathrm{DC} / \mathrm{AC}$ or $\mathrm{AC} / \mathrm{AC}$ converter has to be applied.

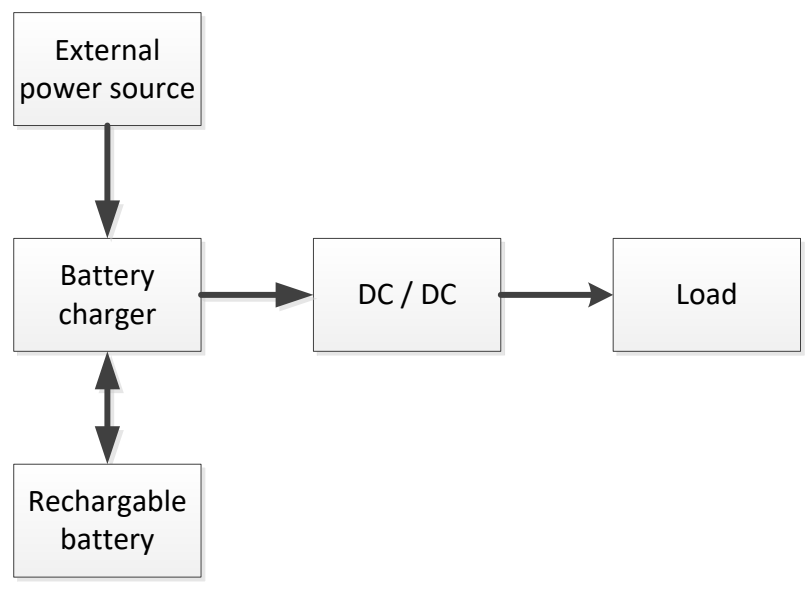

Figure 1

Modular power supply structure

\subsubsection{Redundant Power Supply Unit}

For single-redundant PSU (see Figure 2), if one of the PSU fails, the backup PSU takes over the task. This means that only one PSU is working at a time and that it supplies $100 \%$ of the required electricity for the powered system. In this case, the backup power supply is out of service or under test. This design ensures that the power supply is fault tolerant. This mode is also called, hot-stand-by mode. 


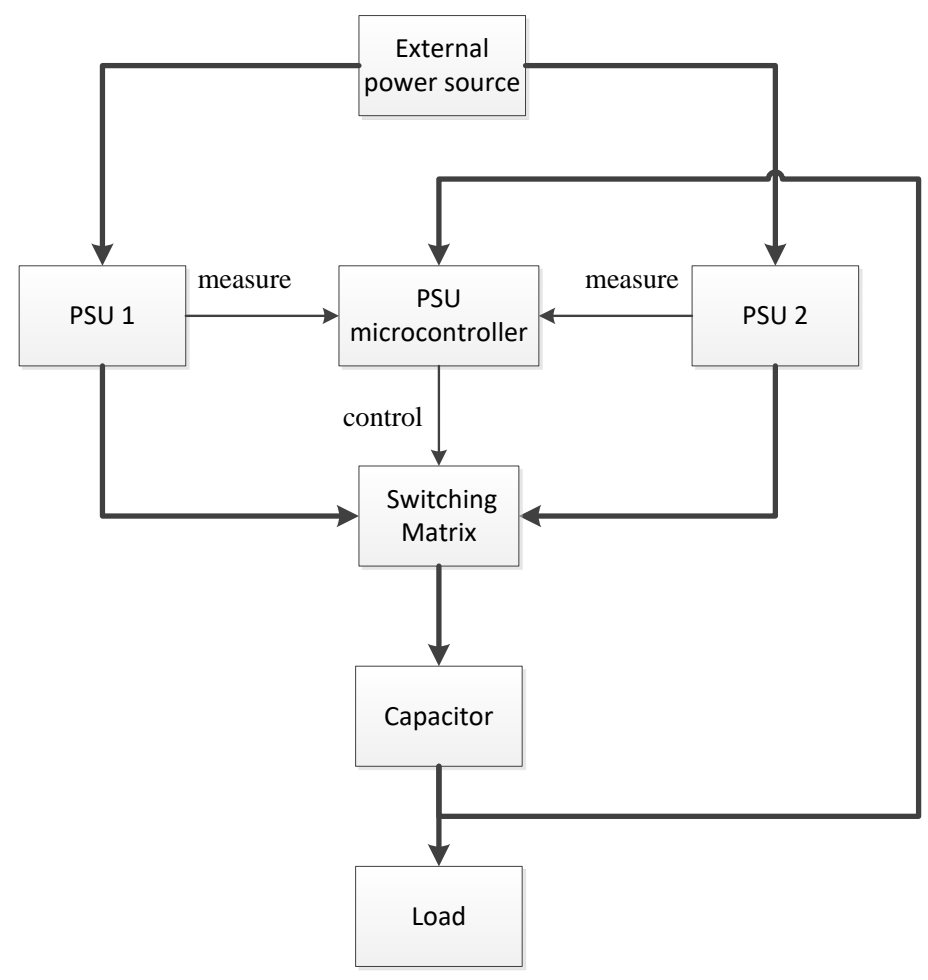

Figure 2

Redundant power supply structure with supervisor MCU

Another solution is the load-sharing mode, where power supplies share the load power. If there are more than two power supplies in the system and one is out of service for failure, replacement, or testing, the remaining power supplies will share the total load current equally.

For example, if there are four redundant PSUs in the power supply system and one of them, for the above mentioned reasons, goes out of service, the power supplies that are still in operation, will distribute the load, so, for example, the single units would provide $33 \%$ instead of $25 \%$ of the load current. All power supplies would be able to provide full load current if left alone in the power supply system.

\subsubsection{Redundant Modular PSU}

On the Figure 3, it can be seen, the capacitor supplies power to the microcontroller, which supervises the PSU, the connected load, and other optional modules, when the power supply is temporarily interrupted due to replacement of the redundant modules. 


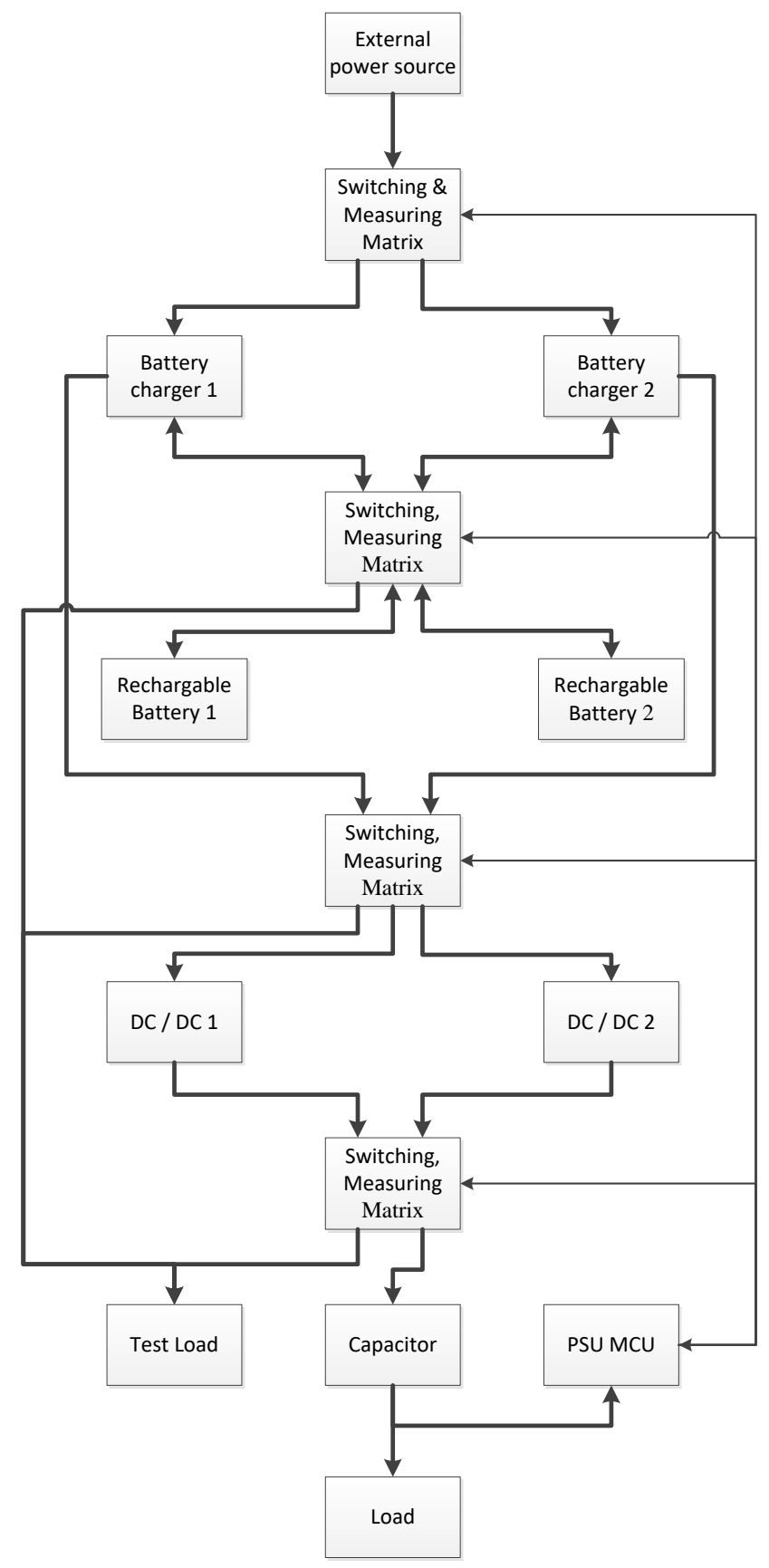

Figure 3

Simplified redundant modular power supply unit structure 


\subsubsection{Microcontroller}

Power supplies usually include a microcontroller that affects the power supply and provides measurement, logging, communication, etc. functions as well.

In the case of modular power supplies, the power supply control microcontroller and the tightly-coupled components may be provided as separate modules or may be part of the motherboard.

For redundant power supplies or redundant modular power supplies, the microcontroller for power supply control extends to monitoring, testing, evaluating the power supplies or power supply modules, and controlling switching matrices.

\subsubsection{Switching Matrix}

The microcontroller also controls the switching matrices that connect the power modules. The function of the switching matrices is to provide energy flow between the power modules in a reconfigurable manner. The switching matrices can be used to connect and disconnect redundant power modules, including replacing redundant power modules.

When replacing power modules, switching multiple redundant power modules in a way that would lead to a short circuit should be avoided. The first step is to disconnect the currently active module, after which the redundant module can be turned on. The process results in a short-term power line break, but with the addition of energy storage devices (buffer capacitors), the power supply is continuously maintained, and transient-low switching is possible. In the experimental setup galvanically isolated relay modules were used. In case of the end product it is recommended to use modern technology based semiconductor switching elements [29]-[31].

\subsection{Measuring Method}

In redundant fault tolerant systems, some basic features are needed for proper operation. In hot-stand-by mode or load-sharing mode, the embedded monitoring system must be able to notify a supervisor and a control system of the actual status or failure of power supplies and modules.

The embedded monitoring system must be able to monitor power supplies and modules. Depending on the various aspects of error detection, this may occur using normal operational load or dummy load. Both the normal operation and the test operation must be measured with active and standby power modules. This can be done by swapping the power modules or by intermittently disabling them, as in a test procedure. 
Redundant fault tolerant power supply systems must be provided with continuous power supply even when defective modules are replaced. The hot-plug-in function ensures smooth operation of the powered system.

\subsubsection{Module Measurement}

During the measurement of the modular power supply, the module's efficiency, temperature, input and output voltage and current values and waveforms must be monitored. The measured values should be transmitted to the microcontroller for further processing and storage.

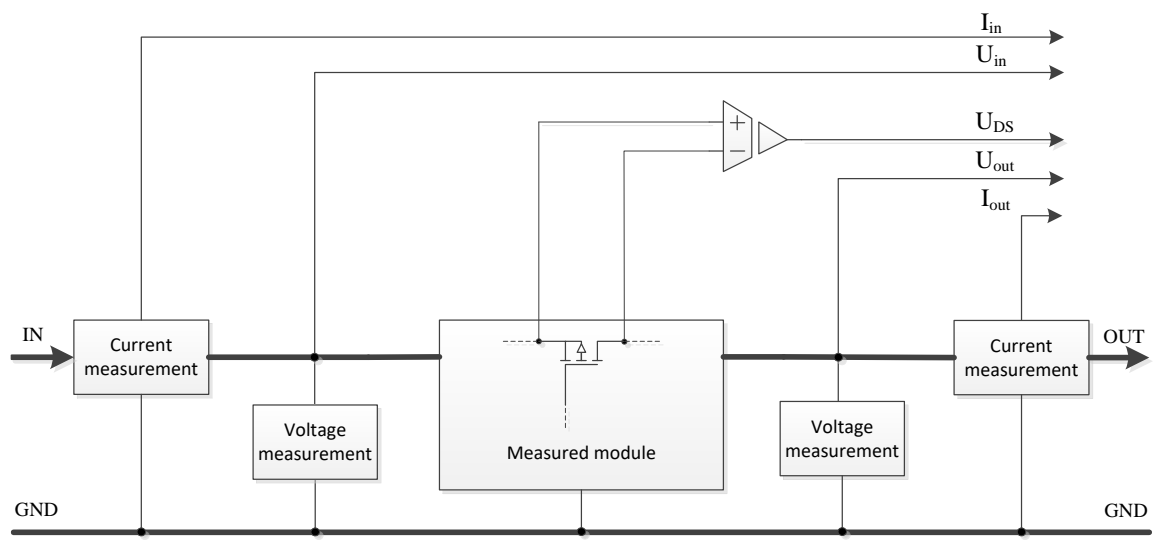

Figure 4

Module measurement scheme

Voltage measurement, if higher than the reference voltage of the analog digital converter of the microcontroller, is carried out by a voltage divider made of high precision and stable elements. There is even the possibility of using an optocoupler, but the brightness degradation of its built-in semiconductor LED, typically in the infrared range, can over time falsify the measurement.

Current measurement can be accomplished by measuring or calculating the differential voltage across Shunt resistors with lower cost. In order to reduce the number of test cables or to measure higher current values, it is also possible to use hall sensors, which have the disadvantage of higher costs.

For lifetime prediction, the voltage difference of the semiconductor drain-source shown in Figure 4 is also measured when the MOSFET is open. When the MOSFET is closed, the drain-source voltage can easily be higher than the input of the operational amplifier used to measure the voltage difference, so the measurement must be constructed with a galvanically isolated operational amplifier. 


\subsubsection{Analog Measurements}

The measurement and evaluation of the power modules can be accomplished by using integrated hardware elements, which support the measurement. They can also detect overcurrent, overvoltage, voltage drop, voltage fluctuation, instability, voltage loss and other anomalies.

The configuration provides additional options for controlling the output voltage and for detecting common differences listed below:

- After a positive voltage spike, the output voltage returns to normal

- After a positive voltage spike, the output voltage will remain above normal (see Figure 5)

- The output voltage remains stably higher than normal, after a voltage surge

- After a negative voltage spike, the output voltage returns to normal (see Figure 6)

- After a negative voltage spike, the output voltage remains below normal

- The output voltage gradually decreases

- The output voltage fluctuates below normal level

- The output voltage remains stable below a normal level after a voltage drop (see Figure 7)

- $\quad$ The output voltage becomes unstable (see Figure 8)

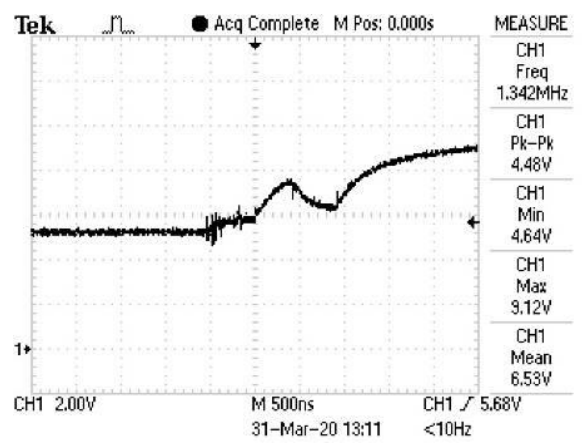

Figure 5

A positive voltage spike, and the output voltage will remain above normal level

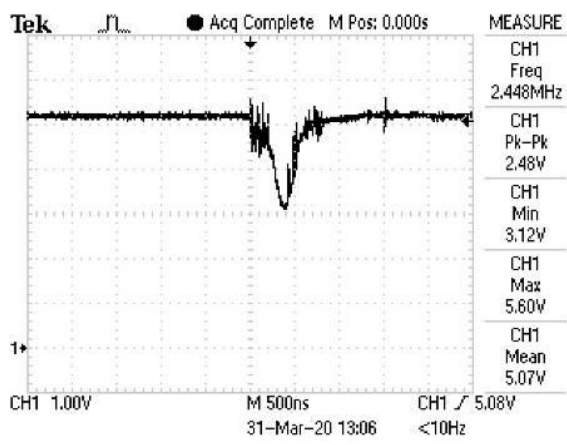

Figure 6

Negative voltage spike the output voltage will remain normal 


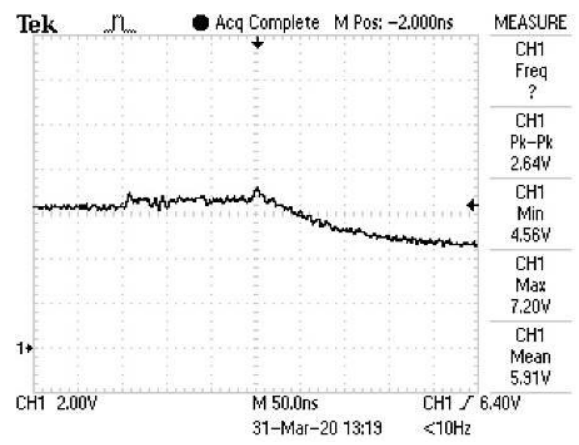

Figure 7

The output voltage remains stable below a normal level after a voltage drop

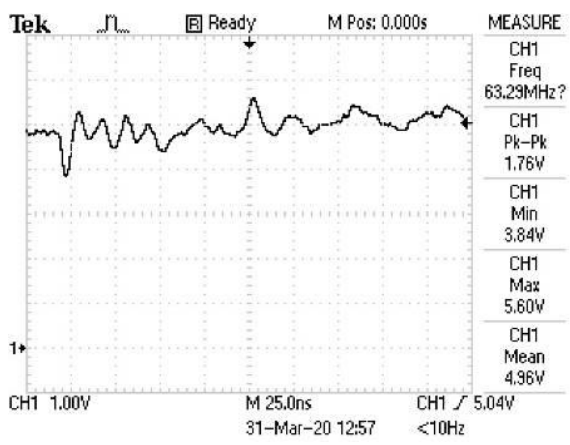

Figure 8

Unstable output voltage

\subsubsection{Multiplexing Analog Lines}

The microcontroller that monitors the power supply and controls the switching matrices has a limited number of terminals and is required to expand due to the large number of measurement and control signals. Extending the number of control outputs is easily accomplished with a serial I/O extender IC. The analog signals to be measured are coupled via an analog multiplexer to the ADC terminals of the microcontroller.

Choosing a more advanced microcontroller eliminates the need for external hardware, with sufficient software (multiplexing the input terminals to the ADC peripheral) to implement the solution presented. If the microcontroller has multiple internal ADC peripherals, it is recommended to measure the same analog signals with the same ADC modules - to avoid measurement errors due to differences in measurement peripherals. If the microcontroller has one internal ADC periphery, a sample and hold ( $\mathrm{SH})$ circuit is necessary to be used. 


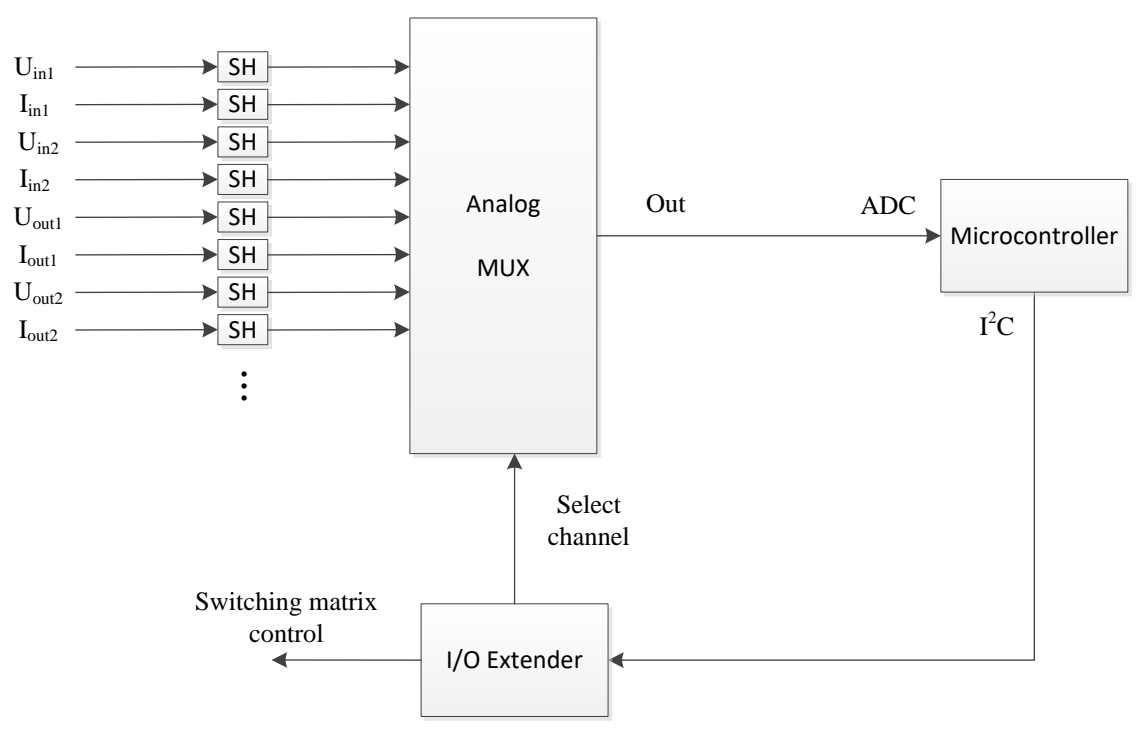

Figure 9

Hardware measurement and control scheme

\subsubsection{External Interrupt Subsystem}

Most of the time, the microcontroller controlling the power supply is in sleep mode. During sleep mode or when executing an instruction, you may not be able to detect unexpected voltage fluctuations in the power supply. Due to the architecture of the interrupt request system, which is designed as an external hybrid circuit, it is able to continuously monitor the output voltage state and, for example, to request an interrupt from the microcontroller in case of voltage fluctuation outside the specified limit.

Unlike the block diagram shown in Figure 1, the use of a built-in comparator as the internal periphery of the microcontroller controlling the power supply is recommended, in which case the reference voltage can be set as a register content by software. The internal comparator peripheral of the microcontroller also has the ability to request an interrupt (see Figure 10). 


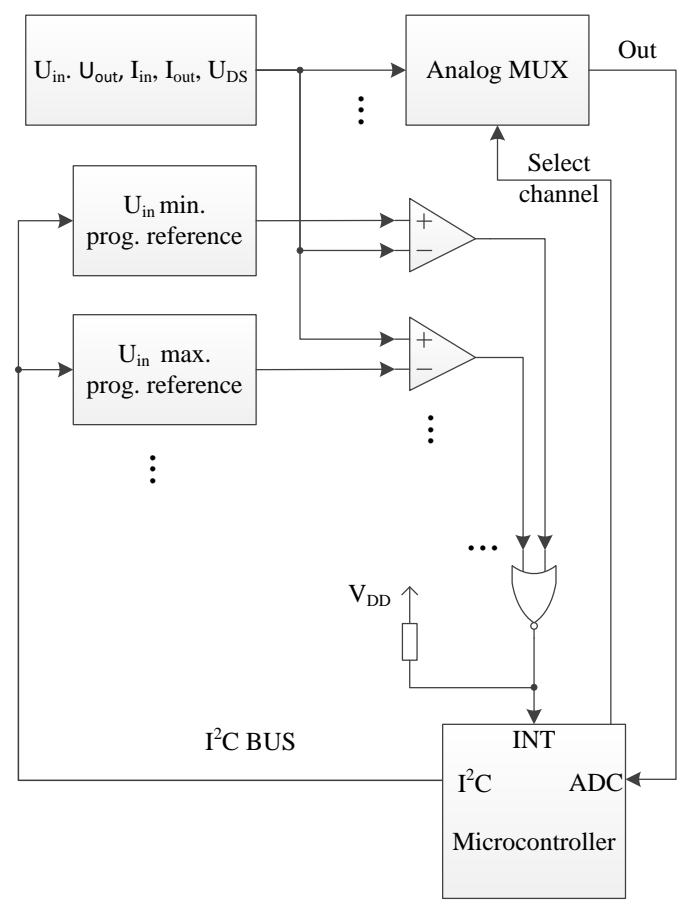

Figure 10

Block diagram of the external interrupt system

\section{Realization}

\subsection{Main Program}

The monitoring system calculates the primary and secondary power of the modules by measuring the input and output voltages and currents of the power supply modules. Based on these measurements, it calculates the efficiency of the power supply modules. If this value is below a predetermined level, or based on several measurements, it can be determined from the stored results that the condition of the unit is deteriorating (the efficiency value drops below a certain level), the monitoring system will send an error message to the monitoring system and jumps to a subroutine.

The monitoring system must process a significant amount of data. The costeffective microcontroller-observed monitoring system can measure only one point at a time, and the analog-to-digital conversion takes a finitely long time. Power 
modules have relatively large number of measurement points. The frequency of each measurement and the accuracy of analog-to-digital conversion (measurement time) can be dynamically changed for efficient operation.

In case the error of a measurement point shows only a slight deviation from the ideal, it can be checked at a lower frequency and with less accuracy, so monitoring the measurement point takes only a small amount of time in the cycle. If the error of the measuring point increases, for example, on the basis of a lookup table, it is recommended to increase the frequency and the accuracy of the measurement. If the rate of change of the error at the measurement point increases, it is recommended to further increase the measurement frequency and accuracy of the measurement point to monitor the change. Measured and stored data can be used to perform fault prediction functions.

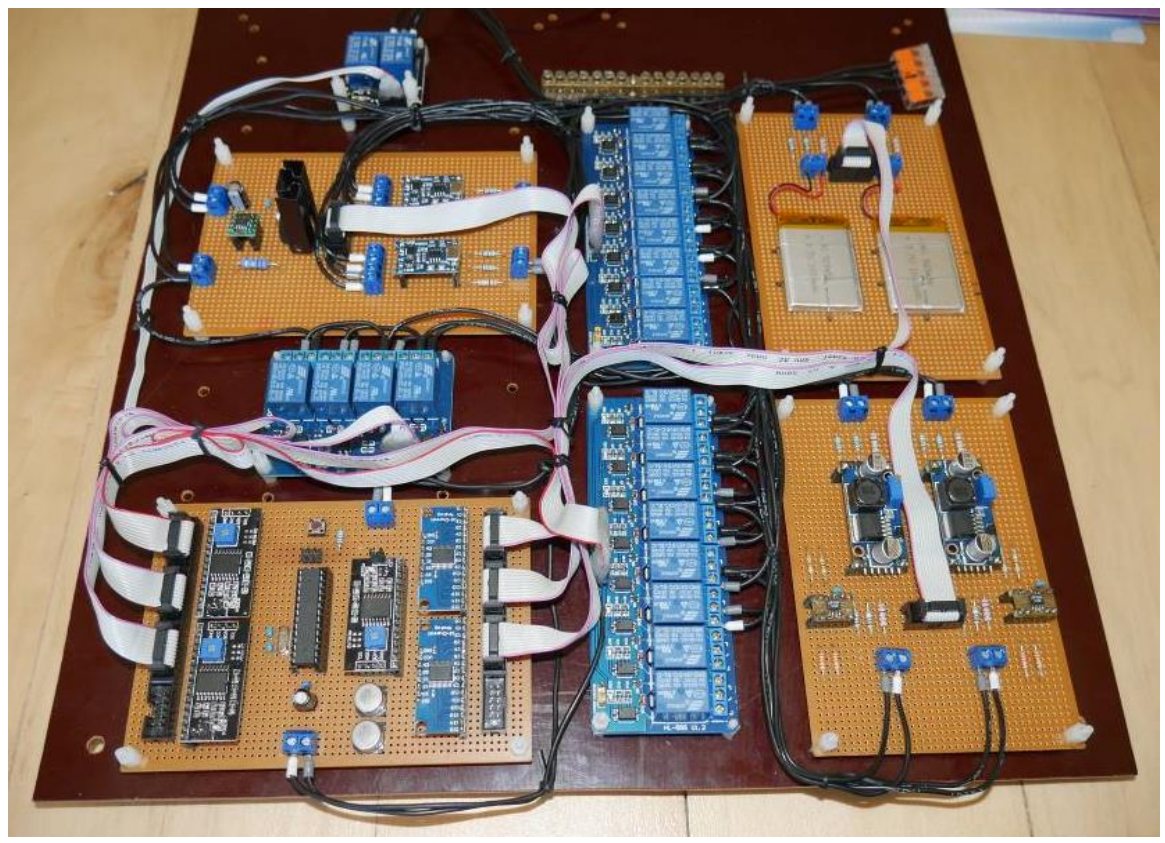

Figure 11

The model circuit

\subsection{Operation Modes}

The software supports user settings. The user has the ability to select the mode of operation and to weigh the following considerations (see Figures 11 and 12). 
In case the user wants to maximize the life of the device, because maintenance is difficult, access to the device is difficult or the goal is to reduce the carbon footprint, you choose Swapping mode with reduced maximum charging and discharging currents. The swapping modules subroutine switches between redundant elements primarily based on the efficiency of the modules, but it can also change based on the temperature of the modules (the temperature of the active module increases), thus saving parts from heat stress and faster aging.

With advanced user settings, it is possible to fine-tune the above-mentioned parameters, customize reference levels, hysteresis values and timings.

If higher reliability is the main goal, it is recommended to activate Simultaneously running mode. In this case, the redundant modules run at 50-50\% load. The heat load is higher than in the previous case. If one module fails, the other takes over $100 \%$ of the load with a smaller transient.

This type of control is recommended for powering easily maintainable equipment. In the case of a module failure, the failure of one of the modules increases the likelihood of a failure of the module remaining in the system, and in the case of the failure of the remaining $100 \%$ load module there are no spare modules in the system. The $100 \%$ load should only be tolerated by the module remaining in the system until maintenance, so we may use a lower power margin than in Swapping or Backup mode.

The third mode of operation is a classic Backup Mode. The module that builds the primary power supply will operate until it fails, after which the backup module will take over the load. In this case, the backup module may remain reliable for a long time due to higher performance margin compared to the Simultaneously running mode, although it does not include a spare element after the failure of the backup module.

This control mode is used to drive the primary active module till failure or till a predetermined degradation of efficiency, thus the long-term power consumption of this control mode will be the highest.

In all three cases, especially in the Backup Mode, it is important to periodically test the modules and determine their functionality. Measurements can be made with the programmatically variable load or with relatively short operation of the inactive module, until reaching the operating temperature, to perform measurements during normal operation. 


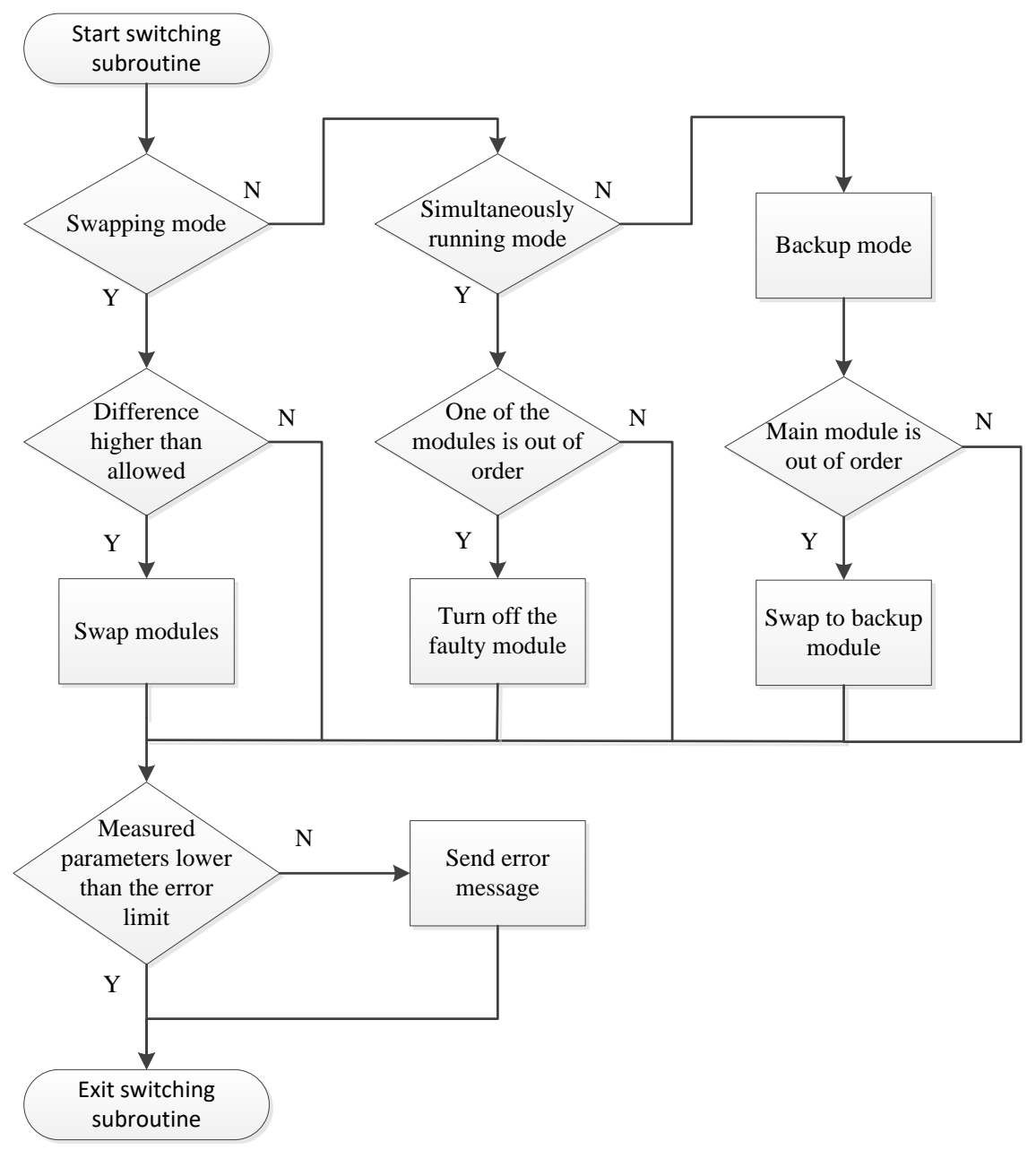

Figure 12

Mode selector algorithm

\section{Conclusions}

The presented redundant power supply, greatly increases the reliability of the device. A cost-effective solution that monitors itself and a modular architecture that greatly enhances upgrades and maintainability, which can significantly increase the life of the equipment, thus, reducing global emissions/waste. The Authors believe that the presented system architecture, can be successfully implemented for both Civil and Industrial applications and especially for applications that demand a high level of reliability. 


\section{Acknowledgement}

The Authors wish to thank the support to the Arconic Foundation. Bertalan Beszédes thankfully acknowledge the financial support by the ÚNKP-19-3 New National Excellence Program of the Ministry for Innovation and Technology, GINOP-2.2.1-15-2018-00015 and GINOP-2.2.1-15-2017-00098 projects. Károly Széll thankfully acknowledge the financial support of this work by the Hungarian State and the European Union under the EFOP-3.6.1-16-2016-00010 and GINOP2.2.1-15-2017-00073 projects.

\section{References}

[1] M. Kolcun, A. Gawlak, M. Kornatka, and Z. Čonka, “Active and Reactive Power Losses in Distribution Transformers," Acta Polytech. Hung., Vol. 17, No. 1, pp. 161-174, 2020, doi: 10.12700/APH.17.1.2020.1.9

[2] "Energy Efficiency 2019," IEA, Paris, 2019. Accessed: Mar. 26, 2020 [Online] Available: https://webstore.iea.org/download/direct/2891

[3] “Energy Efficiency Indicators 2019," IEA, Paris, 2019. Accessed: Mar. 26, 2020 [Online] Available: https://webstore.iea.org/download/direct/2707?fileName=Energy_Efficienc y_Indicators_2019_Highlights.pdf

[4] World Energy Balances 2019. Paris: IEA, 2019

[5] World Energy Statistics 2019. Paris: IEA, 2019

[6] G. Györök, Programozható analóg áramkörök mikrovezérlö környezetben, Vol. 1, Székesfehérvár: Óbudai Egyetem, 2013

[7] É. Hajnal, "Big Data Overview and Connected Research at Óbuda University Alba Regia Technical Faculty," in AIS 2018 - 13 ${ }^{\text {th }}$ International Symposium on Applied Informatics and Related Area, 2018, pp. 1-4

[8] T.-M. I. Băjenescu and M. I. Bazu, Reliability of Electronic Components: A Practical Guide to Electronic Systems Manufacturing. Berlin Heidelberg: Springer-Verlag, 1999

[9] Z. Gao, C. Cecati, and S. X. Ding, "A Survey of Fault Diagnosis and FaultTolerant Techniques-Part I: Fault Diagnosis With Model-Based and Signal-Based Approaches," IEEE Trans. Ind. Electron., Vol. 62, No. 6, pp. 3757-3767, Jun. 2015, doi: 10.1109/TIE.2015.2417501

[10] Z. Gao, C. Cecati, and S. X. Ding, "A Survey of Fault Diagnosis and FaultTolerant Techniques-Part II: Fault Diagnosis With Knowledge-Based and Hybrid/Active Approaches," IEEE Trans. Ind. Electron., Vol. 62, No. 6, pp. 3768-3774, Jun. 2015, doi: 10.1109/TIE.2015.2419013

[11] W. Kong, Y. Luo, Z. Qin, Y. Qi, and X. Lian, "Comprehensive Fault Diagnosis and Fault-Tolerant Protection of In-Vehicle Intelligent Electric 
Power Supply Network," IEEE Trans. Veh. Technol., Vol. 68, No. 11, pp. 10453-10464, Nov. 2019, doi: 10.1109/TVT.2019.2921784

[12] J. Hu, J. Wang, J. Zeng, and X. Zhong, "Model-Based Temperature Sensor Fault Detection and Fault-Tolerant Control of Urea-Selective Catalyst Reduction Control Systems," Energies, Vol. 11, No. 7, p. 1800, Jul. 2018, doi: 10.3390/en11071800

[13] P. Szcześniak, G. Tadra, and Z. Fedyczak, "Model Predictive Control of Hybrid Transformer with Matrix Converter," Acta Polytech. Hung., Vol. 17, No. 1, pp. 25-40, 2020, doi: 10.12700/APH.17.1.2020.1.2

[14] L. R. Neukirchner, A. Magyar, A. Fodor, N. D. Kutasi, and A. Kelemen, "Constrained Predictive Control of Three-PhaseBuck Rectifiers," Acta Polytech. Hung., Vol. 17, No. 1, pp. 41-60, 2020, doi: 10.12700/APH.17.1.2020.1.3

[15] H. Chen and S. Lu, "Fault Diagnosis Digital Method for Power Transistors in Power Converters of Switched Reluctance Motors," IEEE Trans. Ind. Electron., Vol. 60, No. 2, pp. 749-763, Feb. 2013, doi: 10.1109/TIE.2012.2207661

[16] N. M. A. Freire, J. O. Estima, and A. J. Marques Cardoso, "Open-Circuit Fault Diagnosis in PMSG Drives for Wind Turbine Applications," IEEE Trans. Ind. Electron., Vol. 60, No. 9, pp. 3957-3967, Sep. 2013, doi: 10.1109/TIE.2012.2207655

[17] M. Shahbazi, E. Jamshidpour, P. Poure, S. Saadate, and M. R. Zolghadri, "Open- and Short-Circuit Switch Fault Diagnosis for Nonisolated DC-DC Converters Using Field Programmable Gate Array," IEEE Trans. Ind. Electron., Vol. 60, No. 9, pp. 4136-4146, Sep. 2013, doi: 10.1109/TIE.2012.2224078

[18] A. M. Stanisavljević, V. A. Katić, B. P. Dumnić, and B. P. Popadić, “A Comprehensive Overview of Digital Signal Processing Methods for Voltage Disturbance Detection and Analysis in Modern Distribution Grids with Distributed Generation," Acta Polytech. Hung., Vol. 16, No. 5, Aug. 2019, doi: 10.12700/APH.16.5.2019.5.8

[19] X. Xiang, C. Yu, and Q. Zhang, "On intelligent risk analysis and critical decision of underwater robotic vehicle," Ocean Eng., Vol. 140, pp. 453465, Aug. 2017, doi: 10.1016/j.oceaneng.2017.06.020

[20] R. Ghimire, C. Zhang, and K. R. Pattipati, "A Rough Set-Theory-Based Fault-Diagnosis Method for an Electric Power-Steering System," IEEEASME Trans. Mechatron., 2018, doi: 10.1109/TMECH.2018.2863119

[21] P. Lezanski and M. Pilacinska, "The dominance-based rough set approach to cylindrical plunge grinding process diagnosis," J. Intell. Manuf., Vol. 29, No. 5, pp. 989-1004, Jun. 2018, doi: 10.1007/s10845-016-1230-1 
[22] A. Soualhi, G. Clerc, and H. Razik, "Detection and Diagnosis of Faults in Induction Motor Using an Improved Artificial Ant Clustering Technique," IEEE Trans. Ind. Electron., Vol. 60, No. 9, pp. 4053-4062, Sep. 2013, doi: 10.1109/TIE.2012.2230598

[23] B. M. Ebrahimi, M. Javan Roshtkhari, J. Faiz, and S. V. Khatami, "Advanced Eccentricity Fault Recognition in Permanent Magnet Synchronous Motors Using Stator Current Signature Analysis," IEEE Trans. Ind. Electron., Vol. 61, No. 4, pp. 2041-2052, Apr. 2014, doi: 10.1109/TIE.2013.2263777

[24] J. K. Scott, G. R. Marseglia, L. Magni, R. D. Braatz, and D. M. Raimondo, "A hybrid stochastic-deterministic input design method for active fault diagnosis," in 52 ${ }^{\text {nd }}$ IEEE Conference on Decision and Control, Dec. 2013, pp. 5656-5661, doi: 10.1109/CDC.2013.6760780

[25] Y. Song and B. Wang, "Survey on Reliability of Power Electronic Systems," IEEE Trans. Power Electron., Vol. 28, No. 1, pp. 591-604, Jan. 2013, doi: 10.1109/TPEL.2012.2192503

[26] S. Yang, A. Bryant, P. Mawby, D. Xiang, L. Ran, and P. Tavner, "An Industry-Based Survey of Reliability in Power Electronic Converters," IEEE Trans. Ind. Appl., Vol. 47, No. 3, pp. 1441-1451, May 2011, doi: 10.1109/TIA.2011.2124436.

[27] G. Györök, "The FPAA realization of analog robust electronic circuit," in 2009 IEEE International Conference on Computational Cybernetics (ICCC), Jan. 2009, pp. 179-183, doi: 10.1109/ICCCYB.2009.5393941

[28] P. Holcsik, J. Pálfi, Z. Čonka, and M. Avornicului, "A Theoretical Approach to The Implementation of Low-Voltage Smart Switch Boards," Acta Polytech. Hung., Vol. 16, No. 4, Jul. 2019, doi: 10.12700/APH.16.4.2019.4.7

[29] G. T. Orosz, A. Sulyok, G. Gergely, S. Gurbán, and M. Menyhard, "Calculation of the Surface Excitation Parameter for $\mathrm{Si}$ and $\mathrm{Ge}$ from Measured Electron Backscattered Spectra by Means of a Monte-Carlo Simulation," Microsc. Microanal., Vol. 9, No. 4, pp. 343-348, Aug. 2003, doi: $10.1017 / \mathrm{S} 1431927603030241$

[30] G. T. Orosz et al., "Experimental determination of electron inelastic scattering cross-sections in Si, Ge and III-V semiconductors," Vacuum, Vol. 71, No. 1, pp. 147-152, May 2003, doi: 10.1016/S0042207X(02)00729-7

[31] G. Gergely et al., "Surface excitation correction of the inelastic mean free path in selected conducting polymers," Appl. Surf. Sci., Vol. 252, No. 14, pp. 4982-4989, May 2006, doi: 10.1016/j.apsusc.2005.07.017 